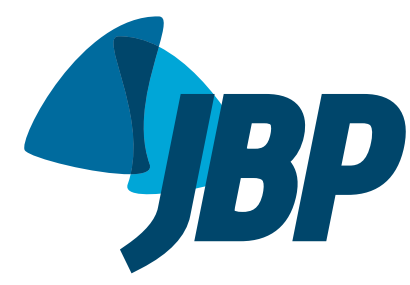

1. Servicio Clínico de Neumología Oncológica, Instituto Nacional de Enfermedades Respiratorias, Ciudad de México, México.

2. División de Posgrado, Facultad de Medicina, Universidad Nacional Autónoma de México. Ciudad de México, México.

3. Servicio de Anatomía Patológica, Instituto Nacional de Enfermedades Respiratorias, Ciudad de México, México.

Submitted: 21 October 2016 Accepted: 4 May 2017

Study carried out at the Servicio Clínico de Neumología Oncológica, Instituto Naciona de Enfermedades Respiratorias, Ciudad de México, México.

\title{
Accuracy of closed pleural biopsy in the diagnosis of malignant pleural effusion
}

\author{
Renata Báez-Saldaña ${ }^{1,2}$, Uriel Rumbo-Nava1, Araceli Escobar-Rojas², \\ Patricia Castillo-González ${ }^{1}$, Santiago León-Dueñas ${ }^{1}$, Teresa Aguirre-Pérez ${ }^{1}$, \\ María Eugenia Vázquez-Manríquez ${ }^{3}$
}

\begin{abstract}
Objective: Previous studies have demonstrated that closed pleural biopsy (CPB) has a sensitivity of less than $60 \%$ for diagnosing malignancy. Therefore, controversy has recently emerged regarding the value of CPB as a diagnostic test. Our objective was to assess the accuracy of CPB in diagnosing malignancy in patients with pleural effusion. Methods: This was a prospective 8-year study of individuals who underwent CPB to establish the etiology of pleural effusion. Information on each patient was obtained from anatomopathological reports and medical records. When CPB findings showed malignancy or tuberculosis, the biopsy was considered diagnostic, and that was the definitive diagnosis. In cases in which biopsy histopathological findings were nonspecific, a definitive diagnosis was established on the basis of other diagnostic procedures, such as thoracoscopy, thoracotomy, fiberoptic bronchoscopy, biochemical and cellular measurements in pleural fluid, and/or microbiological tests. The accuracy of CPB was determined with $2 \times 2$ contingency tables. Results: A total of 1034 biopsies from patients with pleural effusion were studied. Of those, 171 (16.54\%) were excluded from the accuracy analysis either because of inadequate samples or insufficient information. The results of the accuracy analysis were as follows: sensitivity, 77\%; specificity, $98 \%$; positive predictive value, 99\%; negative predictive value, $66 \%$; positive likelihood ratio, 38.5; negative likelihood ratio, 0.23 ; pre-test probability, 2.13; and post-test probability, 82. Conclusions: CPB is useful in clinical practice as a diagnostic test, because there is an important change from pre-test to post-test probability.

Keywords: Biopsy; Pleural effusion, malignant/diagnosis; Pleural effusion, malignant/ epidemiology
\end{abstract}

\section{INTRODUCTION}

Previous evidence has demonstrated that the performance of blind closed pleural biopsy (CPB) as a diagnostic test for malignancy is poor, since the reported sensitivity is less than $60 \%$; therefore, in some countries, CPB is considered obsolete and its use tends to disappear. ${ }^{(1,2)}$

Currently, the interventional pulmonologist has two options for obtaining histological samples of pleural tissue: CPB or medical thoracoscopy. The first is an old technique, ${ }^{(3,4)}$ and the second is currently considered the gold standard(2); however, both procedures have advantages and disadvantages. The CPB described by Cope and Abrams ${ }^{(3,4)}$ in the mid-20th century is an alternative method of obtaining pleural tissue without the need for a surgical procedure. Its use for more than 5 decades is attributed to its ease of performance, its low cost, the tolerability by the patient, and the fact that, within a short period of time, it allows a decision about the management of the case. ${ }^{(5)}$ Nevertheless, it is a purely diagnostic procedure, which does not bring any gains in terms of treatment or symptom relief to the patient as occurs with medical thoracoscopy or video-assisted thoracoscopy.
At our institution, approximately 400 new cases of intrathoracic malignancy are diagnosed every year, and, of those, approximately $40 \%$ have pleural effusion. The initial approach to pleural effusion is to perform a thoracentesis so that the pleural fluid can be analyzed biochemically and cytologically. In cases of nondiagnostic thoracentesis and in the presence of lymphocytic exudate, a definitive diagnosis is established by histopathological analysis of samples obtained by image-guided or non-image-guided CPB or by video-assisted thoracoscopy.

Because at our hospital we continue to perform CPB in cases of lymphocytic exudative pleural effusion of unknown etiology, the objective of the present study was to assess the accuracy of CPB in establishing a diagnosis of malignancy in patients under investigation for pleural effusion.

\section{METHODS}

This was a prospective study of patients with pleural effusion who underwent CPB to establish the etiology of the effusion, over an 8-year period at a referral hospital for respiratory diseases in Mexico City. The study was approved by the Research Ethics Committee of the Instituto Nacional de Enfermedades Respiratorias. 
Before CPB, pleural fluid analysis including biochemical measurements such as protein, lactic dehydrogenase, and cholesterol levels was performed to classify the effusion as an exudate or transudate ${ }^{(6)}$; in addition, other measurements such as glucose, adenosine deaminase, and $\mathrm{pH}$ levels were performed, as were cell counts and cytological studies.

CPB was performed by different pulmonologists with 5 to 15 years of experience and by second- or third-year residents in pulmonary medicine of the emergency and inpatient departments. When CPB was performed by residents, these residents were always directed and supervised by the pulmonologist in charge of the patient. The diagnostic procedure was performed with a Cope ${ }^{(3)}$ or Abrams $^{(4)}$ needle in patients with submassive or massive pleural effusion, in a hospitalization procedure room or in the emergency department. With the patient in a sitting position, his/her arms resting on a table, at shoulder level, the entry point was determined on the affected side. In general, the entry point was located between the posterior axillary line and the line of the inferior angle of the scapula, in the fifth intercostal space. With aseptic technique and local anesthesia (lidocaine $2 \%$ ) of the skin, subcutaneous cellular tissue, intercostal muscle, and underlying region of the parietal pleura, a thoracentesis was performed to ensure that the pleural space had been entered; subsequently, a 3- to 5-mm incision was made with a scalpel blade on the skin and subcutaneous tissue to facilitate the insertion of the biopsy needle along and above the superior border of the inferior rib, so as to avoid damage to the intercostal neurovascular bundle.

The Abrams needle consists of three parts: an outer 11 -gauge cannula ( $3 \mathrm{~mm}$ in outer diameter); an inner 13-gauge stylet that facilitates transparietal insertion; and a 13-gauge hooked needle for taking the biopsy.

When the stylet needle was withdrawn, there was an outflow of pleural fluid, which confirmed successful entry into the pleural cavity. With the cannula in the pleural space, the trocar needle was inserted through it into the pleural space, the notch of the trocar being positioned opposite the said needle grip. To collect a sample of parietal pleura, the said notch engaged the pleura, and with a rotating movement of the trocar needle, the required sample was cut off and taken. These steps were repeated as many times as the number of samples desired.

The Cope needle consists of four parts: an 11-gauge outer cannula $3 \mathrm{~mm}$ in diameter; a 13-gauge hooked biopsy trocar; a beveled trocar; and an inner stylet. After a syringe was attached to the hooked biopsy trocar, the inner stylet was inserted into the beveled trocar, and both were inserted through the outer cannula into the pleural space. The hooked biopsy trocar, to whose outer end a syringe had been attached, was inserted through the outer cannula into the pleural space. Entry into the pleural space was confirmed by aspiration of fluid into the syringe. The parietal pleura was hooked with the biopsy trocar, and, with a slight outward pulling motion, the biopsy was taken.
With either needle, between 4 and 8 samples were taken clockwise at 3, 6, and 9 o'clock, but never at 12 o'clock to avoid damage to the intercostal neurovascular bundle. The biopsies were placed in 3.7\% formaldehyde solution for histopathological examination, which was performed by different pathologists from the pathology department with more than 10 years of experience in diagnosing pulmonary, pleural, and mediastinal diseases. Initially, the biopsies were analyzed morphologically, and, subsequently, they were evaluated immunohistochemically, with appropriate antibody panels for the diagnosis of different neoplastic and non-neoplastic diseases.

The identification of the cases in which CPB was performed was obtained from the records of the anatomical pathology department of the hospital. Information regarding each patient, such as general characteristics, history, clinical profile, radiological findings, and results of cytological and cytochemical study of pleural fluid, was obtained from the inpatient medical records.

When CPB results showed malignancy or tuberculosis, the biopsy was considered diagnostic, and that was the definitive diagnosis in the medical record. In cases of lymphocytic exudates with CPB histopathological findings of nonspecific inflammatory changes (nonspecific chronic inflammation or reactive mesothelial hyperplasia), a definitive diagnosis was established on the basis of other diagnostic procedures, which, for these cases, were the following: invasive procedures such as thoracoscopy, thoracotomy, fiberoptic bronchoscopy, adenosine deaminase levels, and/or microbiological tests for pyogenic bacteria and for Mycobacterium tuberculosis; or the clinical criterion and specific laboratory studies according to the case.

In all cases, CPB histopathological findings were compared with the definitive diagnosis made by the treating physician and 6-month follow-up data, on the basis of medical records.

Pleural tuberculosis was defined as the presence of at least one of the following: a finding of granulomas on pleural biopsy; a positive Ziehl-Neelsen staining of pleural fluid or biopsy material; a positive LöwensteinJensen culture of pleural fluid; a positive sputum smear microscopy; or an adenosine deaminase level of $>45$ IU in a pleural exudate with a lymphocyte predominance of $>80 \%$.

Parapneumonic pleural effusion was defined as the presence of a pleural exudate with a predominance of polymorphonuclear cells in addition to a clinical profile consistent with pneumonia; the case was treated with antibiotics, and there was improvement at discharge.

\section{Statistical analysis}

For the accuracy analysis of CPB, we used $2 \times$ 2 contingency tables in which the results of the diagnostic test were compared with respect to the presence or absence of any intrathoracic malignant disease and with respect to the presence or absence of mesothelioma alone. 
We calculated sensitivity, specificity, positive and negative predictive values, positive and negative likelihood ratios, and pre-test and post-test probabilities. ${ }^{(7)}$

\section{RESULTS}

During the study period, 1,034 CPBs were performed in 1,034 patients with pleural effusion. The mean age of the patients was $57 \pm 17$ years, 615 (59.48\%) were male, and $419(40.52 \%)$ were female. Malignancy was identified in $466(45.07 \%)$ of the patients, among whom lung adenocarcinoma and mesothelioma were the most common neoplasms, being found in 252 $(24.37 \%)$ and $105(10.16 \%)$, respectively (Table 1$)$.

Of the 1034 CPBs, 171 (16.54\%) were excluded from the accuracy analysis: 72 (6.96\%) because of inadequate samples, given that no pleural tissue was obtained; and $99(9.57 \%)$ because of lack of information about the case, since case follow-up until the establishment of a definitive diagnosis was impossible.

Among the final diagnoses of the 863 cases included in the accuracy analysis, the most common were lung adenocarcinoma, mesothelioma, and undifferentiated carcinoma (Table 2).

CPB results, by presence or absence of any intrathoracic malignant disease and by presence or absence of mesothelioma, as well as results for the diagnostic test performance indicators for each case, are described in $2 \times 2$ contingency tables (Tables 3 and 4).

Table 1. Histopathological results for 1,034 closed pleural biopsies.

\begin{tabular}{|c|c|}
\hline Result & n (\%) \\
\hline \multicolumn{2}{|l|}{ Malignant neoplasm } \\
\hline Lung adenocarcinoma & $252(24.37)$ \\
\hline Mesothelioma & $105(10.16)$ \\
\hline Undifferentiated carcinoma & $53(5.12)$ \\
\hline Small cell lung cancer & $19(1.84)$ \\
\hline Giant cell lung cancer & $6(0.58)$ \\
\hline Epidermoid carcinoma & $5(0.48)$ \\
\hline Hodgkin and non-Hodgkin lymphoma & $11(1.06)$ \\
\hline Other neoplasms ${ }^{\mathrm{a}}$ & $15(1.45)$ \\
\hline Total & $466(45.07)$ \\
\hline \multicolumn{2}{|l|}{ Infectious disease } \\
\hline Tuberculosis & $116(11.22)$ \\
\hline Parapneumonic pleural effusion & $2(0.19)$ \\
\hline Total & $118(11.41)$ \\
\hline \multicolumn{2}{|l|}{ Other results } \\
\hline Nonspecific inflammation ${ }^{b}$ & $378(36.56)$ \\
\hline $\begin{array}{l}\text { Inadequate biopsy sample (no pleural } \\
\text { tissue) }^{c}\end{array}$ & $72(6.96)$ \\
\hline Total & $450(43.52)$ \\
\hline
\end{tabular}

aOther neoplasms included sarcomas and metastasis from clear cell renal, breast, and ovarian cancer. ' It refers to findings of non-specific acute and chronic inflammation and reactive mesothelial hyperplasia. cThese biopsies were excluded from the accuracy analysis.
In $38 / 863$ cases $(4.40 \%)$, there were complications ( 3 cases had two complications): 30 cases had pneumothorax, of which 19 did not require pleural tube placement and 11 did; 6 patients developed a hematoma at the puncture site; 2 had vasovagal syncope; and 3 developed subcutaneous emphysema in the area surrounding the puncture site.

\section{DISCUSSION}

The results of this study describe, according to modern clinical epidemiology, the performance of CPB in cases of lymphocytic exudative pleural effusion of unknown etiology. This diagnostic test proved useful since it allowed the identification of $77 \%$ of the cases of pleural effusion due to any malignancy and $81 \%$ of those due to mesothelioma. Lung adenocarcinoma metastatic to the pleura and mesothelioma were the most commonly diagnosed neoplasms by this method. The specificity of the diagnostic test under study was high, since only $2 \%$ of the patients with other causes of pleural effusion had a positive result for malignancy and none had a positive result for mesothelioma. Likewise, in a patient with a positive CPB result for neoplastic disease, the actual probability of having a neoplasm was $99 \%$ and that of having a mesothelioma was $100 \%$. However, in clinical practice, the confidence with which it is possible to rule out the probability of a thoracic neoplasm, given a normal result or a result with nonspecific inflammatory changes, is very important in a setting where the prevalence of the disease is high,

Table 2. Diagnoses of 863 cases with completed followup for identification of a definitive diagnosis, for accuracy analysis of closed pleural biopsy.

\begin{tabular}{|c|c|}
\hline Result & n (\%) \\
\hline \multicolumn{2}{|l|}{ Malignant neoplasm } \\
\hline Lung adenocarcinoma & $317(36.73)$ \\
\hline Mesothelioma & $130(15.06)$ \\
\hline Small cell lung cancer & $26(3.01)$ \\
\hline Hodgkin and non-Hodgkin lymphoma & $20(2.32)$ \\
\hline Undifferentiated carcinoma & $41(4.75)$ \\
\hline Epidermoid carcinoma & $15(1.74)$ \\
\hline Giant cell carcinoma & $6(0.70)$ \\
\hline Other neoplasms ${ }^{\mathrm{a}}$ & $32(3.71)$ \\
\hline Total & $587(68.02)$ \\
\hline \multicolumn{2}{|l|}{ Infectious diseases } \\
\hline Tuberculosis & $141(16.34)$ \\
\hline Parapneumonic pleural effusion & $50(5.79)$ \\
\hline Total & $191(22.13)$ \\
\hline \multicolumn{2}{|l|}{ Other diseases } \\
\hline Others $^{\mathrm{b}}$ & $70(8.11)$ \\
\hline Idiopathic & $15(1.74)$ \\
\hline Total & $85(9.85)$ \\
\hline
\end{tabular}

aOther neoplasms included sarcomas; metastasis from clear cell renal, breast, and ovarian cancer; germ cell tumors; and papillary thyroid cancer. bother nonneoplastic diseases included rheumatoid arthritis; systemic lupus erythematosus; renal, hepatic, and cardiogenic failure; pneumoconiosis; pachy pleuritis; and pulmonary thromboembolism. 
Table 3. Closed pleural biopsy results, by presence or absence of any intrathoracic malignant disease, and accuracy analysis. ${ }^{a}$

\begin{tabular}{|c|c|c|c|}
\hline Biopsy result & $\begin{array}{l}\text { Presence of } \\
\text { malignancy }\end{array}$ & $\begin{array}{l}\text { Absence of } \\
\text { malignancy }\end{array}$ & Total \\
\hline Diagnostic biopsy & 450 & 5 & 455 \\
\hline Non-diagnostic biopsy & 137 & 271 & 408 \\
\hline Total & 587 & 276 & 863 \\
\hline \multicolumn{4}{|c|}{ Test performance indicator } \\
\hline $\begin{array}{l}\text { Sensitivity } \\
\qquad a /(a+c)=450 / 587\end{array}$ & & \multicolumn{2}{|c|}{$77 \%$ (95\% Cl: 74-79) } \\
\hline $\begin{array}{l}\text { Specificity } \\
\qquad d /(b+d)=271 / 276\end{array}$ & & \multicolumn{2}{|c|}{ 98\% (95\% Cl: 97-99) } \\
\hline $\begin{array}{l}\text { Positive predictive value } \\
\qquad \mathrm{a} /(\mathrm{a}+\mathrm{b})=450 / 455\end{array}$ & & \multicolumn{2}{|c|}{ 99\% (95\% Cl: 98-100) } \\
\hline $\begin{array}{l}\text { Negative predictive value } \\
\qquad d /(c+d)=271 / 408\end{array}$ & & \multicolumn{2}{|c|}{$66 \%$ (95\% Cl: 63-70) } \\
\hline $\begin{array}{l}\text { Positive likelihood ratio } \\
\text { Sensitivity } /(1-\text { specificity })=77 / 2\end{array}$ & & \multicolumn{2}{|r|}{38.5} \\
\hline $\begin{array}{l}\text { Negative likelihood ratio } \\
\quad(1-\text { sensitivity }) / \text { specificity }=23 / 98\end{array}$ & & \multicolumn{2}{|r|}{0.23} \\
\hline $\begin{array}{l}\text { Prevalence } \\
\qquad(a+c) /(a+b+c+d)=587 / 863\end{array}$ & & \multicolumn{2}{|c|}{ 68\% (95\% Cl: 65-71.3) } \\
\hline $\begin{array}{l}\text { Pre-test probability } \\
\quad \text { Prevalence } /(1-\text { prevalence })=68 / 32\end{array}$ & & \multicolumn{2}{|r|}{2.13} \\
\hline $\begin{array}{l}\text { Post-test probability } \\
\text { Pre-test probability } \times \text { positive likelih }\end{array}$ & ratio $=2.13 \times 38.5$ & \multicolumn{2}{|r|}{82} \\
\hline
\end{tabular}

a: true-positive results; b: false-positive results; c: false-negative results; and d: true-negative results. amesothelioma is included.

Table 4. Closed pleural biopsy results, by presence or absence of mesothelioma, and accuracy analysis.

$\begin{array}{lccc}\text { Biopsy result } & \begin{array}{c}\text { Presence of } \\ \text { mesothelioma }\end{array} & \begin{array}{c}\text { Absence of } \\ \text { mesothelioma }\end{array} & \text { Total } \\ \text { Diagnostic biopsy } & 105 & 0 & 105 \\ \text { Non-diagnostic biopsy } & 25 & 733 & 758 \\ \text { Total } & 130 & 733 & 863\end{array}$

Sensitivity

$$
\mathrm{a} /(\mathrm{a}+\mathrm{c})=105 / 130
$$

Specificity

$d /(b+d)=733 / 733$

Positive predictive value $a /(a+b)=105 / 105$

Negative predictive value $d /(c+d)=733 / 758$

Positive likelihood ratio Sensitivity $/(1-$ specificity $)=81 / 99$

Negative likelihood ratio $(1-$ sensitivity $) /$ specificity $=19 / 100$

Prevalence

$$
(a+c) /(a+b+c+d)=130 / 863
$$

Pre-test probability Prevalence $/(1-$ prevalence $)=15 / 85$

Post-test probability

Pre-test probability $\times$ positive likelihood ratio $=0.18 \times 82$
$81 \%$ (95\% Cl: 78-83)

$100 \%$

$100 \%$

97\%(95\% Cl: 96-98)

\section{2}

0.19

$15 \%$ (95\% Cl: $13-17)$

14.8

a: true-positive results; b: false-positive results; c: false-negative results; and d: true-negative results.

as is our case, to such an extent that a negative result does not exclude the probability of a neoplasm in 34\% of cases. The usefulness of this diagnostic procedure lies in the possibility of excluding malignancy in cases of lymphocytic exudative pleural effusion on the basis of a biopsy result showing nonspecific chronic inflammation or reactive mesothelial hyperplasia. Our series and other published series report a high number of such results (20\%-60\% $)^{(8-13)}$; in some such cases malignancy is subsequently confirmed by other methods, those 
Table 5. Performance of different methods of obtaining pleural tissue samples for the diagnosis of intrathoracic malignancy-related pleural effusion.

\begin{tabular}{|c|c|c|c|c|}
\hline Reference & Technique & Number of patients & $\begin{array}{c}\text { Diagnostic } \\
\text { performance }\end{array}$ & $\begin{array}{l}\text { Frequency of } \\
\text { complications* }\end{array}$ \\
\hline \multicolumn{5}{|c|}{ Studies of diagnosis of malignant pleural effusion } \\
\hline Poe et al., $1984^{(8) a}$ & CPB & 211 & $\begin{array}{l}\text { Sn: } 68 \% \\
\text { Sp: } 99 \% \\
\text { PPV: } 98 \% \\
\text { NPV: } 77 \%\end{array}$ & $9.9 \%$ \\
\hline Chakrabati et al., $2006^{(9)}$ & CPB & 75 & $\begin{array}{c}\text { Sn: } 51 \% \\
\text { Sp: } 100 \% \\
\text { PPV: } 100 \% \\
\text { NPV: } 100 \%\end{array}$ & $11 \%$ \\
\hline Pereyra et al., 2013(10) & CPB & 658 & $\begin{array}{c}\text { Sn: } 33.9 \% \\
\text { Sp and PPV: } 100 \% \\
\text { NPV: } 71 \%\end{array}$ & $14.4 \%$ \\
\hline Botana et al., 2013 & $\begin{array}{c}\text { CPB vs. } \\
\text { US-guided CPB }\end{array}$ & $\begin{array}{c}67 \\
114\end{array}$ & $\begin{array}{c}\text { Sn: } 60 \% \\
\text { Sn: } 77.4 \%\end{array}$ & $\begin{array}{c}1 / 67(1.5 \%) \\
3 / 114(2.5 \%)\end{array}$ \\
\hline Maskell et al., $2013^{(1)}$ & $\begin{array}{l}\text { CPB vs. } \\
\text { CT-guided CPB } \\
\text { Clinical trial }\end{array}$ & $\begin{array}{l}25 \\
25\end{array}$ & $\begin{array}{l}\text { Sn: } 47 \% \text { vs. } 87 \% \\
\text { Sp: } 100 \% \text { vs. } 100 \% \\
\text { NPV: } 44 \% \text { vs. } 80 \% \\
\text { PPV: } 100 \% \text { vs. } 100 \%\end{array}$ & $\begin{array}{l}\text { CPB } 1 / 25 \\
\text { CT } 0\end{array}$ \\
\hline Son et al., 2014(12) & $\begin{array}{l}\text { CPB vs. } \\
\text { MT }\end{array}$ & $\begin{array}{l}36 \\
31\end{array}$ & $\begin{array}{l}55.6 \% \\
93.5 \%\end{array}$ & $\begin{array}{c}7 / 36(19.4 \%) \\
0\end{array}$ \\
\hline Haridas et al., 2014(14) & $\begin{array}{l}\text { Clinical trial } \\
\text { MT vs. } \\
\text { CPB }\end{array}$ & $\begin{array}{l}29 \\
29\end{array}$ & $\begin{array}{l}\text { Sn: } 86.2 \% \\
\text { Sn: } 62.1 \%\end{array}$ & $\begin{array}{l}10.3 \% \\
17.2 \%\end{array}$ \\
\hline Metintas et al., 2010(16) & $\begin{array}{c}\text { Clinical trial } \\
\text { MT vs. } \\
\text { CT-guided pleural } \\
\text { biopsy }\end{array}$ & $\begin{array}{l}62 \\
62\end{array}$ & $\begin{array}{l}\text { Sn: } 94.1 \% \\
\text { Sn: } 87.5 \%\end{array}$ & $\begin{array}{l}11 / 62 \\
14 / 62\end{array}$ \\
\hline Present study & $\begin{array}{l}\text { CPB for any } \\
\text { malignancy }\end{array}$ & 863 & $\begin{array}{l}\text { Sn: } 77 \% \\
\text { Sp: } 98 \% \\
\text { PPV: } 99 \% \\
\text { NPV: } 66 \%\end{array}$ & $4.40 \%$ \\
\hline \multicolumn{5}{|c|}{ Studies of diagnosis of mesothelioma } \\
\hline Boutin et al., 1993 ${ }^{(15)}$ & $\begin{array}{l}\text { RTLA vs. } \\
\text { CPB }\end{array}$ & $\begin{array}{l}188 \\
145\end{array}$ & $\begin{array}{l}\text { Sn: } 98 \% \\
\text { Sn: } 21 \%\end{array}$ & $\begin{array}{c}4.8 \% \\
-\cdots-\end{array}$ \\
\hline Heilo et al., $1999^{(13)}$ & US-guided biopsy & 70 & $\begin{array}{l}\text { Sn: } 77 \% \\
\text { Sp: } 88 \% \\
\text { PPV: } 100 \% \\
\text { NPV: } 57 \%\end{array}$ & $\begin{array}{l}\text { No severe } \\
\text { complications }\end{array}$ \\
\hline Adams et al., $2001^{(17)}$ & $\begin{array}{c}\text { US- or CT-guided } \\
\text { biopsy }\end{array}$ & 53 & $\begin{array}{l}\text { Sn: } 86 \% \\
\text { Sp: } 100 \%\end{array}$ & $2 / 53$ \\
\hline Present study & $\begin{array}{c}\text { CPB for } \\
\text { mesothelioma }\end{array}$ & 863 & $\begin{array}{l}\text { Sn: } 81 \% \\
\text { Sp: } 100 \% \\
\text { PPV: } 100 \% \\
\text { NPV: } 97 \%\end{array}$ & $4.40 \%$ \\
\hline
\end{tabular}

CPB: closed pleural biopsy; Sn: sensitivity: Sp: specificity; PPV: positive predictive value; NPV: negative predictive value; US: ultrasound; MT: medical thoracoscopy; and RTLA: rigid thoracoscopy under local anesthesia. ${ }^{\text {a Diagnoses of }}$ malignancy and tuberculosis are included.

being false-negatives for malignancy. In the present study, 378 biopsies (36.56\%) showed nonspecific inflammatory changes, and, in the accuracy analysis, $137 / 587$ (23.34\%) corresponded to false-negative results for malignancy.

The explanation for such false-negative results lies in the fact that neoplasms disseminate in patches in the pleura in cases of intrathoracic malignancy, the effusion is due to obstruction of pleural or mediastinal lymphatics, or the disease involves only the visceral pleura. Among the neoplasms for which false-negative $\mathrm{CPB}$ results occurred most often were several varieties of intrathoracic sarcomas and neoplasms of mediastinal and metastatic extrathoracic origin, such as metastasis from clear cell renal, breast, and ovarian cancer, germ cell tumors, and papillary thyroid cancer.

On the basis of the positive likelihood ratio, a patient with a lymphocytic pleural exudate and a CPB result positive for malignancy will be 38.5 times more likely to have a malignant chest disease compared with a patient 
with the same characteristics but with a negative $\mathrm{CPB}$ result. Finally, there was a large difference between pre- and post-test probability, 2.13 and 82 , respectively, which suggests clinically important displacement. A similar trend was observed for mesothelioma.

Previous studies on the performance of $\mathrm{CPB}$ in diagnosing malignancy, whether addressing CPB alone or comparing it with image-guided or medical thoracoscopy-guided techniques, have demonstrated that CPB with Cope or Abrams needles allows the diagnosis of $21 \%$ to $62 \%$ of cases of neoplasm-related pleural effusion $(1,8-12,14,15)$ (Table 5). When pleural biopsy is performed under image guidance, whether ultrasound or computed tomography, it consistently shows better performance, with sensitivity between $77 \%$ and $87.5 \%,(1,11,13,16,17)$ and when there is pleural thickening greater than $1 \mathrm{~cm}$, sensitivity increases to $95 \%$, a value similar to that achieved when biopsy is obtained with thoracoscopy. ${ }^{(16)}$ In general, specificity and positive predictive values are high for CPB and for that performed under image guidance. In our study, sensitivity for neoplastic disease (77\%) was higher than that reported in previous studies and was within the range reported for image-guided pleural biopsy (Table 5), and, similar to previous studies, specificity and positive predictive value were high in the present study. This is probably due to the fact that the place where our study was conducted is a referral hospital for respiratory diseases and many of the cases present with advanced stages of the disease.

Medical thoracoscopy and video-assisted thoracoscopy are considered the gold-standard methods of obtaining biopsies in cases of neoplasm-related pleural effusion. ${ }^{(5)}$ For medical thoracoscopy, evidence shows sensitivity ranging from 86.2 to $93.5 \%{ }^{(12,14,16)}$ (Table 5).

There have been few studies assessing the accuracy of CPB in diagnosing mesothelioma. One study compared the performance of CPB with that of surgical thoracoscopy and found sensitivity of $21 \%$ vs. $98 \%$. ${ }^{(15)}$ When biopsy is performed under image guidance such as ultrasound or computed tomography, sensitivity increases to $77 \%$ and $86 \%$, respectively ${ }^{(13,17)}$ (Table 5). The above results contrast with those of the present study, since the CPB performance indicator values for the diagnosis of mesothelioma were high and even similar to image-guided biopsy results. ${ }^{(13,17)}$ This performance can be explained in part by the fact that many of the cases had pleural thickening.
Our study confirms the safety of CPB and its accessibility even to pulmonologists in training. The frequency of complications was $4.40 \%$ (Table 5 ), similar to that reported in the literature ${ }^{(2)}$; on the other hand, we demonstrated the performance of CPB in a routine work setting, given that biopsy collection and histopathological analysis were performed independently by different health care workers.

At our institution, CPB is still part of the diagnostic algorithm of patients with lymphocytic exudative pleural effusion for identification of etiology, although we have video-assisted thoracoscopy, whose performance is much better than that of CPB and which in addition facilitates performing therapeutic procedures, such as pleurodesis to prevent effusion recurrence, concurrently with biopsy collection; however, video-assisted thoracoscopy takes more time and resources and may be a risk factor in patients with high anesthetic risk.

Medical thoracoscopy is not yet available at our institution, and image-guided pleural biopsy is not often performed because it requires equipment, whether ultrasound or computed tomography equipment, and trained personnel. Currently at our institution we are attempting to generalize the performance of CPB under image guidance, whether ultrasound or computed tomography, as well as to implement the use of medical thoracoscopy.

One of the limitations of the present study is that cytology results, culture results, and radiographic findings such as pleural thickening were not included in the analysis, being considered only in including cases in the study and in the definitive diagnosis. Another potential limitation is the number of cases excluded from the analysis, which can undoubtedly affect the test performance indicators; nevertheless, we consider that we have a good sample size that includes more than $80 \%$ of all cases reported during the study period and therefore estimate that the change in the test performance indicators would be modest and would not ostensibly affect the trend of results.

In conclusion, at the facility where the present study was conducted, CPB proved to be valid, accurate, and precise in establishing the diagnosis of intrathoracic malignancy in patients with pleural effusion. CPB is useful in clinical practice as a diagnostic test, because there is an important change from pre-test to post-test probability.

\section{REFERENCES}

1. Maskell NA, Gleeson FV. Davies RJ. Standard pleural biopsy versus CT-guided cutting-needle biopsy for diagnosis of malignant disease in pleural effusions: a randomised controlled trial. Lancet. 2003;361(9366):1326-30. https://doi.org/10.1016/S01406736(03)13079-6

2. Dixon G, de Fonseka D, Maskell N. Pleural controversies: image guided biopsy vs. thoracoscopy for undiagnosed pleural effusions? J Thorac Dis. 2015;7(6):1041-51.

3. Cope C. New pleural biopsy needle; preliminary study. JAMA. 1958;167(9):1107-8. https://doi.org/10.1001/ jama.1958.72990260005011a
4. Abrams LD. A pleural-biopsy punch. Lancet. 1958;1(7010):30-1 https://doi.org/10.1016/S0140-6736(58)92521-2

5. Koegelenberg CF, Diacon AH. Pleural controversy: closed needle pleural biopsy or thoracoscopy-which first? Respirology. 2011;16(5):738-46. https://doi.org/10.1111/j.1440 1843.2011.01973.x

6. Light RW. Clinical practice. Pleural effusion. N Engl J Med 2002;346(25):1971-7. https://doi.org/10.1056/NEJMcp010731

7. Straus SE, Richardson WS, Glasziou P, Haynes RB. Diagnóstico y cribado. In: Straus SE, Richardson WS, Glasziou P, Haynes RB. 3rd edition, Medicina basada en la evidencia. Elsevier España; 2006; 
p. $67-100$

8. Poe R, Israel RH, Utell MJ, Hall WJ, Greenblatt DW, Kallay MC Sensitivity, specificity, and predictive values of closed pleural biopsy. Ann Intern Med. 1984;144(2):325-8. https://doi.org/10.1001/ archinte.1984.00350140139020

9. Chakrabarti B, Ryland I, Sheard J, Warburton CJ, Earis JE. The role of the Abrams percutaneous pleural biopsy in the investigation of exudative pleural effusions. Chest. 2006;129(6):1549-55. https://doi. org/10.1378/chest.129.6.1549

10. Pereyra MF, San-José E, Ferreiro L, Golpe A, Antúnez J, GonzálezBarcala FJ, et al. Role of blind closed pleural biopsy in the management of pleural exudates. Can Respir J. 2013;20(5):362-6. https://doi.org/10.1155/2013/731352

11. Botana-Rial M, Leiro-Fernández V, Represas-Represas $C$, GonzálezPiñeiro A, Tilve-Gómez A, Fernández-Villar A. Thoracic ultrasoundassisted selection for pleural biopsy with Abrams needle. Repir Care. 2013;58(11):1949-54. https://doi.org/10.4187/respcare.02378

12. Son HS, Lee SH, Darlong LM, Jung J, Sun K, Kim KT, et al. Is there a role for a needle thoracoscopic pleural biopsy under local anesthesia for pleural effusions? Korean J Thorac Cardiovasc Surg.
2014;:47(2):124-8. https://doi.org/10.5090/kjtcs.2014.47.2.124

13. Heilo A, Stenwig AE, Solheim OP. Malignant pleural mesothelioma: US-guided histologic core-needle biopsy. Radiology. 1999; 211(3):657-9. https://doi.org/10.1148/radiology.211.3.r99jn03657

14. Haridas N, Suraj KP, Rajagopal TP, James PT, Chetambath R. Medical Thoracoscopy vs Closed Pleural Biopsy in Pleural Effusions: A Randomized Controlled Study. J Clin Diagn Res. 2014;8(5):MC01-4.

15. Boutin C, Rey F. Thoracoscopy in pleural malignant mesothelioma: a prospective study of 188 consecutive patients. Part 1: Diagnosis. Cancer. 1993;72(2):389-93. https://doi.org/10.1002/10970142(19930715)72:2<389::AID-CNCR2820720213>3.0.CO;2-V

16. Metintas $M, A k G$, Dundar $E$, Yildirim $H$, Ozkan $R$, Kurt $E$, et al. Medical thoracoscopy vs CT scan-guided Abrams pleural needle biopsy for diagnosis of patients with pleural effusions: a randomized, controlled trial. Chest. 2010;137(6):1362-8. https://doi.org/10.1378/ chest.09-0884

17. Adams RF, Gleeson FV. Percutaneous image-guided cutting-needle biopsy of the pleura in the presence of a suspected malignant effusion. Radiology. 2001;219(2):510-4. https://doi.org/10.1148/ radiology.219.2.r01ma07510 